\title{
Perigos do consumo monótono de sementes pelas aves: Revisão
}

\section{Mariana Jungers Calderaro Nahum ${ }^{1 *}$, André Luiz de Oliveira Faccioni ${ }^{1}$, Bruna Cristina Perticarrari da Silva ${ }^{1}$, Edson Ronaldo Bueno ${ }^{1}$, Maria Carolina Gonçalves Pita ${ }^{2}$}

\author{
${ }^{I}$ Discente do $6^{\circ}$ semestre de Medicina Veterinária - Universidade Guarulhos. \\ ${ }^{2}$ Docente do curso de Medicina Veterinária - Universidade Guarulhos. \\ *Autor para correspondência, E-mail: manahum@uol.com.br
}

\begin{abstract}
RESUMO. Dentre as aves mais comumente criadas em cativeiro como pets, a maioria é granívora, ou seja, se alimentam de grãos ou sementes. As necessidades nutricionais de muitas destas aves não estão bem definidas pela dificuldade de identificar todos os alimentos consumidos pelas mesmas na natureza e em quais proporções, mas já existem rações balanceadas para as espécies mais comumente criadas, todavia, a maioria destes animais ainda é alimentado com sementes, por dificuldade de adaptação da ave à ração e/ou do proprietário em aceitar a mudança, o que causa diversas doenças nutricionais, principalmente quando o consumo é de apenas um tipo de semente, pois nas sementes há ausência ou baixa concentração das vitaminas A, D3, e do complexo B, deficiência de inúmeros minerais, baixa relação entre cálcio e fósforo, além de apresentar altas concentrações de lipídios. Além disso, com o passar do tempo, as sementes perdem muitos de seus nutrientes através da peroxidação. As principais doenças relacionadas ao consumo monótono de sementes são as deficiências de vitamina $\mathrm{A}$, de vitamina $\mathrm{D} 3$, de vitaminas do complexo B, de Biotina, de cálcio, osteodistrofias, dermatopatias nutricionais, obesidade, lipidose hepática, pododermatites e micotoxicoses. Conclui-se que são necessários mais estudos para verificação das necessidades nutricionais de cada espécie e trabalhos para a conscientização da população sobre os benefícios da utilização destas dietas, bem como dos riscos de alimentar aves com apenas um tipo de semente.
\end{abstract}

Palavras chave: Nutrição, silvestres, cativeiro, sementes, doenças nutricionais.

\section{Dangerous of monotonous consumption of seed by wild: Review}

\begin{abstract}
The most of the birds raised in captivity like a pets, are granivorous, and they feeding with grain or seeds. The nutritional needs of many of these birds are not defined by the difficulty of identifying all food consumed by them in nature and in better proportions, but there are already balanced rations for the species most created, however, most of these animals are fed as seeds due to difficulty in adapting the bird to feed and owner to accept change, which causes various nutritional diseases, especially when the consumption is only one type of seed, because the seeds are absent or has low concentrations of vitamins A, D3 and B complex, many minerals deficiency, low ratio of calcium and phosphorus, besides it has a high concentrations of lipids. Also, by the time, the seeds lost many of their nutrients through peroxidation. Major related monotonous consumption of seed diseases are deficiencies of vitamin A, vitamin D3, vitamin B complex, biotin, calcium, osteodystrophy, nutritional skin diseases, obesity, hepatic lipidosis, foot pad lesions and mycotoxicosis. We conclude that further studies are necessary to support the nutritional needs of each species and to raise awareness of the population about the benefits of using these diets as well as the risks of feeding birds with only one kind of seed.
\end{abstract}

Keywords: Nutrition, wild, captive, seeds, nutritional diseases.

\section{Introdução}

De acordo com os hábitos alimentares, as aves são classificadas em granívoros (comedores de 
grãos ou sementes), frugívoros (apenas frutas), onívoros (consomem uma variedade de alimentos, inclusive de origem animal), carnívoros e nectívoros, dentre estes, os mais comumente criados em cativeiro como pet são os granívoros, incluindo passeriformes e pscitacídeos (koutsos et al., 2001).

A alimentação de aves silvestres em cativeiro é dificultada por vários fatores, mesmo o fornecimento de alimentos consumidos na natureza, mas em quantidades superiores pode provocar um fornecimento de energia aumentado (Ullrey et al., 1991). Na natureza, estes animais se alimentam com dieta altamente nutritiva, com teores elevados de ácidos graxos, moderados de proteína e relativamente baixos de carboidratos (Saad et al., 2007). Não há um estudo completo dos requerimentos nutricionais de aves exóticas comumente mantidas em cativeiro, os requerimentos das espécies especificamente são baseados em informações gerais (Cork, 2000). Há disponível no mercado atualmente para as aves mais criadas como pets, rações fareladas, peletizadas e extrusadas, dentre as fareladas as principais desvantagens são grande desperdício e doenças respiratórias relacionadas à inalação do farelo, dentre as peletizadas, a desvantagem é a limitação da inclusão de óleos, já as extrusadas permitem a inclusão de lipídios sem alterar as propriedades físicas do produto, aumenta a digestibilidade e a qualidade do alimento (Dale, 1996; Nunes, 1998).

Entretanto, as aves são relutantes em aceitar a substituição da semente por ração na dieta, pois seus ancestrais provavelmente se alimentavam de sementes, aves em geral não gostam de mudanças e sementes são ricas em gordura, o que as torna muito palatáveis, entretanto aves que recebem apenas rações, não conhecem sementes, e por isso aceitam a dieta com facilidade (Harrison, 1998). Devido a esta relutância da ave associada ao desconhecimento das necessidades nutricionais,e a pouca disponibilidade de alimentos comerciais específicos, é prática comum em criadouros, zoológicos e domicílios a utilização de dietas inespecíficas, que tem sido realizada de maneira empírica, baseando-se na observação de suas preferências e hábitos alimentares na natureza, preocupando-se também com o custo-benefício, desta forma, sementes ainda são muito utilizadas, de acordo com uma pesquisa do Pet Age Magazine, a maioria das aves silvestres mantidas como pet tem suas dietas baseadas em sementes e pesquisas realizadas atualmente comprovam que as sementes com o passar do tempo perdem nutrientes essenciais para a saúde da ave devido à peroxidação (Saad et al., 2007; Harrison, 1998).As principais sementes utilizadas são: alpiste, amendoim, painço e girassol, todavia há grandes riscos no consumo de sementes, especialmente quando o fornecimento é de apenas um tipo de semente, pois nas sementes estão ausentes ou em baixa concentração diversos nutrientes, incluindo vitaminas A e D3, vitaminas do complexo B e inúmeros minerais, também apresentam baixa relação entre cálcio e fósforo, além de apresentar altas concentrações de lipídios(Hess, Mauldin, Rosenthal, 2002; Cubas et al., 2007; Guimarães, 2007; Saad et al., 2007).

As doenças nutricionais apresentam sintomas clínicos semelhantes e em poucas situações o exame clínico isoladamente permite a identificação de qual ou quais nutrientes estão em falta ou excesso, as principais doenças nutricionais citadas são as deficiências protéicas, de vitamina A, E, do complexo B, de Zinco, Cobre, Ferro, Magnésio, Selênio, dermatopatias nutricionais, osteodistrofias, obesidade suas comorbidades, lipidose hepática, gota, hemocromatose, urolitíase, aterosclerose, síndrome do emagrecimento progressivo, micotoxicoses (Carciofi \& Oliveira, 2007).

Tabela 1. Composição química das sementes ${ }^{1}$

\begin{tabular}{lccccc} 
Semente & $\mathrm{MS}^{2}$ & $\mathrm{~PB}^{2}$ & $\mathrm{EE}^{2}$ & $\mathrm{Ca}^{2}$ & $\mathrm{P}^{2}$ \\
\hline Girassol & 95,90 & 24,17 & 57,80 & 0,06 & 1,05 \\
Amendoi & 8,12 & 27,0 & 56,43 & 1,7 & 0,22 \\
$\mathrm{~m}$ & & & & & \\
Alpiste & 17,20 & 20,82 & 6,10 & & \\
Painço & & 13,54 & 3,37 & 1,6 & 2,6 \\
\hline
\end{tabular}

Dados expressos na base da matéria seca.

$\mathrm{MS}=$ matéria seca, $\mathrm{PB}=$ proteína bruta, $\mathrm{EE}=$ extrato etéreo, $\mathrm{Ca}=$ cálcio, $\mathrm{P}=$ fósforo.

Dados obtidos nos estudos de Saad et al.. (2007); Gobbi et al.. (2010); Abrantes et al.. (2011); Paiano et al. (2011); Cleef et al. (2012); Villalobos (2012).

\section{Doenças de origem nutricional}

Os nutrientes participam de diversas funções no metabolismo, sua falta leva as células a alterações metabólicas e estruturais, o que compromete os tecidos e a função dos órgãos, levando às doenças nutricionais. $\mathrm{O}$ diagnóstico destas doenças depende de uma adequada anamnese, exame físico e em alguns casos de 
exames laboratoriais específicos (Carciofi \& Oliveira, 2001).

\section{Deficiências nutricionais}

A deficiência de vitamina A pode causar imunossupressão, problemas visuais (cegueira noturna), lesão da camada epitelial do olho, com o ressecamento e espessamento da conjuntiva, paralisação da secreção dos canais lacrimais, queratinização e opacificação da córnea e, a partir dai, infecção e cegueira irreversível (Borsoi, 1995; Felix, Maiorka \& Sorbara, 2009).

A vitamina D3 pode ser sintetizada pelo animal, quando o mesmo é exposto aos raios ultravioleta, entretanto em aves de cativeiro muitas vezes não são expostas a luz solar de forma adequada, ou pelo tempo necessário, sendo fundamental sua suplementação na dieta. Sua deficiência altera o ganho de peso e a mineralização óssea (Felix, Maiorka \& Sorbara, 2009).

Com relação às vitaminas do complexo $\mathrm{B}$, sua deficiência causa diversas doenças, como a síndrome da morte súbita, alterações de crescimento, deformidades de penas, diarreia, alterações cutâneas, esteatosehepática e lesões no sistema nervoso periférico (Felix, Maiorka \& Sorbara, 2009; Tully Jr, Dorrestein \& Jones, 2010).

Deficiência de biotina é um fator predisponente para o desenvolvimento de dermatite, síndrome do fígado e rins gordurosos, deformidades de membros, alterações de crescimento e empenamento, perose e ataxia (Felix, Maiorka \& Sorbara, 2009; Tully Jr, Dorrestein \& Jones, 2010).

A baixa relação cálcio fósforo encontrada nas sementes, causa alterações ósseas importantes, como a osteodistrofia, isto ocorre porque o cálcio e o fósforo são os principais minerais utilizados no desenvolvimento das aves, associados principalmente ao metabolismo na formação óssea, quando a concentração de cálcio sanguínea cai, o cálcio depositado nos ossos é retirado para elevar o nível sanguíneo, durante a absorção, metabolismo e excreção, cálcio e fósforo devem manter uma relação em torno de $2: 1$, excesso de cálcio interfere na disponibilidade de outros minerais, como o fósforo, magnésio, manganês e zinco causando deficiências secundárias, e altos níveis de fósforo também podem causar deficiência de cálcio (Vargas Jr et al., 2003).

\section{Osteodistrofia}

Osteodistrofia ou alterações osteoarticulares do desenvolvimento são os termos utilizados para denominar alterações que acometem ossos e as articulações, estas podem ocorrer por deficiências nutricionais, como no caso de dietas pobres em cálcio, ou excessivamente ricas em fósforo, ou com menor disponibilidade de cálcio devido a insuficientes níveis de vitamina D ou A. Dentre as osteodistrofias temos a osteoporose, o raquitismo, osteomalácea, osteodistrofia fibrosa e condrodistrofia (Doige, 1990; Carciofi \& Oliveira, 2001).

\section{Dermatopatias nutricionais}

Em aves, sinais comuns são penas opacas e rasgadas, pele espessada e escamosa, principalmente na face, nos pés e ao redor dos olhos e retardo ou interrupção da muda. Há também favorecimento de infecções bacterianas e fúngicas secundárias à desestruturação da barreira de proteção, à alteração na secreção de lípides e da microbiota cutânea. Estas manifestações ocorrem principalmente devido a deficiência de biotina e vitaminas do complexo $\mathrm{B}$, de vitamina $\mathrm{A}$, niacina, ácido pantotênico, zinco, manganês e proteína. (Carciofi \& Oliveira, 2001; Felix, Maiorka \& Sorbara, 2009; Tully Jr, Dorrestein \& Jones, 2010).

\section{Obesidade}

A obesidade ocorre quando a energia consumida excede a energia despendida por um longo período, geralmente ocorre pelo consumo de alimentos calóricos como sementes oleosas e pela falta de exercícios, sendo um problema muito comum nas aves cativas. É um fator de risco para diversas doenças, como a lipidose hepática, infertilidade, doenças do sistema reprodutivo, anormalidades no sistema músculoesquelético, pododermatite plantar, ruptura de ligamentos, hipertensão, disfunção cardiovascular, pancreatite necrótica aguda, diabetes melitus, lipomas, má absorção gastrintestinal e deficiências nutricionais, especialmente de vitaminas lipossolúveis e cálcio (Carciofi \& Oliveira, 2001; Saad et al., 2008; Santos et al., 2012).

\section{Lipidose hepática}

A lipidose hepática, também é conhecida como fígado gorduroso, esteatose hepática, degeneração gordurosa e é bem comum em aves criadas em cativeiro, sua etiologia é multifatorial: doenças debilitantes, anemia crônica, doenças 
metabólicas, obesidade, toxinas químicas e bacterianas estão entre as causas mais frequentes. Geralmente está associado à obesidade, o que reforça sua correlação com fatores nutricionais e metabólicos. Ocorre deposição e o armazenamento excessivo de gordura no fígado, seus sinais clínicos incluem obesidade, empenamento deficiente, dispneia, aumento do volume abdominal, plumagem com textura oleosa, diarréia, arrancamento de pena, crescimento exacerbado de bico e unhas, anorexia, regurgitação, e depressão. Mas há casos em que ocorre o óbito sem outras manifestações clínicas (Couto, 2007; Santos et al., 2012).

\section{Aterosclerose}

Ocorre o espessamento e redução do lúmem de artérias, devido a uma inflamação na camada íntima da parede arterial e o acúmulo de substâncias lipídicas, tecido fibroso, colesterol, detritos celulares, cálcio e outras substâncias, formando as placas de ateroma. É uma doença progressiva que em aves geralmente é diagnosticada na necropsia, pois em geral ocorre morte súbita, sem manifestações clínicas anteriores (Bavelaar \& Beynen, 2004).

Embora a etiologia da aterosclerose tenha sido apontada por muitos anos como sendo o acúmulo progressivo e concêntrico na parede arterial, e tendo como fator de risco o consumo de alimentos gordurosos e a obesidade, atualmente a principal causa da aterosclerose é um processo inflamatório, sabe-se que a agressão sistemática promove respostas que alteram a homeostase do endotélio, que secretam moléculas vasoativas de adesão, citoquinas e fatores de crescimento entre outras substâncias as quais, se o processo de agressão não é bloqueado, continuam a serem produzidas indefinidamente, desta forma sua correlação com a obesidade não é correta, pois esta relacionada a disfunção endotelial, inflamação e proliferação vascular (Albuquerque et al., 2006; Terra \& Costa, 2008).

\section{Pododermatite}

A pododermatite é uma lesão na face plantar dos pés das aves, inicia-se devido a uma abrasão, formando uma lesão eritematosa e pruriginosa que torna-se exsudativa e ulcerativa, ocorrendo infecção bacteriana que pode ser primária ou secundária, acredita-se que em aves criadas em cativeiro a principal causa seja a má-nutrição, ocasionando deficiência protéica, deficiência de vitamina $\mathrm{A}$, das vitaminas do complexo $\mathrm{B}$, unida à obesidade que causa alterações cutâneas como o ressecamento e hiperqueratose. Além disso, a obesidade aumenta a incidência, uma vez que o sobrepeso aumenta a descarga no membro, aumentando a probabilidade de lesão (Kelecom, 2008).

\section{Lipomas}

São tumores que geralmente se apresentam como massas globulares amareladas, de crescimento lento e benigno, não dolorosas, móveis e macias à palpação, sem alteração no tecido cutâneo adjacente. Em geral são encontrados no tecido subcutâneo, mas em algumas aves pode ocorrer em tecidos mais profundos como músculos, órgãos da cavidade celomática, boca e crânio. Apesar de benignos há relatos do aparecimento de novas massas tumorais após a remoção cirúrgica dos focos primários em aves. Em aves, os principais fatores são a obesidade, má nutrição, principalmente relacionada a ingesta de lipídeos e falta de exercícios (Oliveira et al., 2006; Santos et al., 2008).

\section{Micotoxicoses}

As micotoxinas, principalmente as aflatoxinas, são um grupo de metabólitos secundários produzidos por vários fungos filamentosos, principalmente Aspergillus, Penicilliume Fusarium, e que podem causar resposta tóxica se ingeridos por animais, causando as micotoxicoses. Estes fungos são contaminantes presentes em alimentos durante a secagem e estocagem, ou como patógenos de plantas. A contaminação ocorre de forma direta e natural durante todas as etapas de sua obtenção (da colheita ao armazenamento e consumo). Estas aflatoxinas exibem toxicidade aguda e crônica, são potentes agentes carcinogênicos, causando também lesões renais e hepáticas e o consumo de altas doses pode ser letal, sendo o grau dos efeitos adversos determinados não apenas pela concentração das aflatoxinas, mas também pelo tempo de exposição, da quantidade na dieta, do estado nutricional e da espécie envolvida, sendo as aves a espécie mais susceptível (Maia Siqueira, 2007; Simão, 2010).

\section{Conclusão}

Conclui-se que embora existam opções balanceadas para a alimentação de aves mantidas em cativeiro na forma de rações, são necessários mais estudos para verificação das necessidades 
nutricionais de cada espécie e trabalhos para a conscientização da população sobre os benefícios da utilização destas dietas, bem como dos riscos de alimentar aves com sementes, especialmente quando é oferecido apenas um tipo de semente.

\section{Referências Bibliográficas}

Abrantes, F.L; Kulczynski, S.M.; Soratto, R.P.; Barbosa, M.M.M. Nitrogênio em cobertura, teor de proteína e exportação de nutrientes pelos grãos de painço. Biosci. J., Uberlândia, v.27, a.6, p.888-895, nov/dec 2011.

Albuquerque, C.A.; Hoefel Filho, R.; Marques, M.B. \& Rohde, L.E. Vulnerabilidade da doença aterosclerótica de carótidas: mudança de paradigmas?. Scientia Médica, Porto Alegre: PUCRS, v. 16, n.1, jan/mar, 2006.

Andriguetto, J.A.; Perly, L.; Minardi, I. Gemael, A.; Flemming, J.S.; Souza, G.A. \& Bona Filho, A. Nutrição animal. 5.ed., v.1, São Paulo:Nobel, 1996.

Bavelaar, F.J. \& Beynen, A.C. Aherosclerosis in parrots: a review. Vet Quart, v.26, n. 2, p. 5060, 2004.

Borsoi, M.A. Nutrição e dietética: noções básicas. São Paulo: Senac, 1995.

Carciofi, A.C.; Oliveira, L.D. Doenças Nutricionais. In: CUBAS, Z.S. \& Catão-Dias, J.L. (Eds.) Tratado de animais selvagens: medicina veterinária. São Paulo: Roca, 2007, p.838-864.

Cleef, H.C.B; Oliveira, D.; Melina, A.B.; Jane, N.D.E. \& Gonçalves, J.S. Determinação do teor de extrato etéreo de grãos de oleaginosas através de diferentes processamentos. Rev. Electronica de Veterinaria. Malaga, Espanha. v.13, n.3, p.0-6, 2012.

Cork, S.C. Iron storage diseases in birds. Avian Pathology. 29: 7-12, 2000.

Cruz, O.L.M.; Pessoto, J.; Pezato, R \&; Alvarenga, E.L. Osteodistrofias do osso temporal: revisão dos conceitos atuais, manifestações clínicas e opções terapêuticas. Rev. Bras. Otorrinolaringol. v.68, n.1, p.119126, jan/fev 2002.

Dale, N. Improving nutriente utilization by ingredient and dietary modification. Word Poultry, v.12, n.2, p.33, 1996.
Doige, C. Sistema Esquelético. In: Thompson, R.G. Patologia Veterinária Especial, São Paulo, Manole, 1990. Cap. 11, p. 531-578.

Felix, A.P.; Maiorkal, A. \& Sorbara, J.O.B. Níveis vitamínicos para frango de corte: Universidade Federal do Paraná (UFPR), Curitiba: Ciência Rural, Santa Maria, v.39, n.2, p.619-626, mar-abr, 2009.

Guimarães, M.B. Passeriformes (Pássaro, Canário, Saíra, Gralha). In: Cubas, Z.S.; Silva, J.C.R. \& Catão-Dias, J.L. (Eds.) Tratado de animais selvagens: medicina veterinária. São Paulo: Roca, 2007, P.324-337.

Gobbi, K.F.; Garcia, R.; Garcez Neto, A.F.; Pereira, O.G. \& Rocha, G.C. Valor nutritivo do capim-braquiária e do amendoim forrageiro submetidos ao sombreamento. Arch. Zootec. v. 59, n. 227, p. 379-390, 2010.

Harrison, G.J. Forty-three years of progress in pet bird nutrition. Journal of the American Veterinary Medical Association, v.212, n.8, p.1226-1230,april 151998.

Hess, L.; Mauldin, G. \& Rosenthal, K. Estimated nutrient content of diets commonly fed to pet birds. The Veterinary Record, v. 150, p.399404, 2002.

Kelecom, P.M. Pododermatite em aves de gaiola. Rio de Janeiro: Universidade Castelo Branco, 2008. Tese (Pós Graduação em Clínica Médica e Cirúrgica de Animais Selvagens e Exóticos da Qualittas - UCB. Universidade Castelo Branco, Rio de Janeiro, 2008.

Koutsos, E.A.; Matson, K.D. \& Klasing, K.C. Nutritionofbirds in the order psittaciformes: a reviw. Journal of Avian Medicine and Surgery. v.15, n. 4, p.257-275, 2001.

Maia, P.P. \& Siqueira, M.E.P.B. Aflatoxinas em rações destinadas a cães, gatos e pássaros uma revisão. Revista da FZVA. Uruguaiana, v.14, n.1, p. 235-257. 2007.

Morrison, F.B. Alimentos e Alimentação dos Animais. São Paulo: Melhoramentos, 1966.

Nunes, I.J. Nutrição animal básica. 2.ed. Belo Horizonte: FEP-MVZ, 1998. p.388, 1998.

Oliveira, F.S.; Martins, L.L.; Delfini, A.; Faria Junior, D.F. Exérese de lipoma em papagaioverdadeiro (Amazona aestiva). Acta Scientiae Veterinariae. v. 34, n. 2, p. 201-203, 2006. 
Paiano, D.; Magalhães, V.J.A.; Magalhães Junior, M.A.A.; Garcia, E.R.M.; Fachinello, M.R. Consumo e valor nutritivo de alimentos utilizados para bicudo-verdadeiro (Sporophilamaximiliani). Rev. Bras. Saúde Prod. Salvador, v.12, n.3, p.750-757, jul/set, 2011.

Saad, C.E.P.; Ferreira, W.M.; Borges, F.M.O.; Lara, L.B. Avaliação do gasto e consumo voluntário de rações balanceadas e semente de girassol para papagaios verdadeiros (Amazona aestiva).Cienc. Agrotec, Lavras, v. 31, n. 4, p. 1176-1183, jul/ago, 2007.

Saad, C.E.P.; Ferreira, W.M.; Borges, F.M.O. \& Lara, L.B. Digestibilidade e retenção de nitrogênio de alimentos para papagaios verdadeiros (Amazona aestiva). Cienc. Agrotec, Lavras, v. 31, n. 5, p. 1500-1505, set/out, 2007.

Saad, C.E.P.; Ferreira, W.M.; Borges, F.M.O. \& Lara, L.B. Energia metabolizável de alimentos utilizados na formulação de rações para papagaios verdadeiros (Amazona aestiva).Cienc. Agrot., Lavras, v.32, n.2, p.591-597, mar/abr 2008.

Santos, G.G.C.; Matuella, G.A.; Coraila, A.M.; Silva, L.C.S.; Lange, R.R. \& Santin, E. Doenças de aves selvagens diagnosticadas na Universidade Federal do Paraná. Pesq. Vet. Bras. v.28, n.11, p. 565-670, nov. 2008.

Santos, R.M.; Campos, A.G.; Penna B.L.; Cury, F.J.; RissatI, G.B. Lipidose hepática em papagaio verdadeiro (amazona aestiva)Relato de caso. IV Congresso de Iniciação Científica Nucleus, Ituverava, v.9, n.2, sup. 355, out. 2012.

Simão, V. Avaliação da qualidade de alimentos para aves de companhia quanto ingredientes, corantes artificiais, fungos e micotoxinas.
Florianópolis: Universidade Federal de Santa Catarina, 2010. Tese (Pós-graduação em ciência dos alimentos). Departamento de ciência e tecnologia de alimentos. Universidade Federal de Santa Catarina, Florianópolis, 2010.

Terra, N.L.; Costa, P.M. Previna-se da aterosclerose. Porto Alegre: EDIPUCRS, 2008. p. 11-16.

Tully Jr, T.N.; Dorrestein, G.M.; Jones, A.K. Clínica de aves. São Paulo: Elsevier, 2010.

Ullrey, D.E.; Allen, M.E.; Baer, D.J. Formulated diets versus seed mixtures for psittacines. Journal of Nutrition, Philadelphia, v.121, n.11S, p. 193-205, 1991.

Vargas Jr, J.G.; Albino, L.F.T.;Rostagno, H.S.; Gomes, P.C.; Cupertino, E.S.; Carvalho, D.C.O; Nascimento, A.H. Níveis nutricionais de calico e fósforo disponível para aves de reposição leves e semipesadas de 0 a 6 semanas de idade. R. Bras. Zootec., v.32, n.6, p.1919-1926, 2003 (Supl.2).

Villalobos, L. Fenologia, producción y valor nutritivo del pasto alpiste (phalarisarundinacea) enla zona alta lechera de Costa Rica. Agron. Costarricense. v. 36, n.1, 2012.

Recebido em Setembro 23, 2014

Aceito em Novembro 4, 2014

License information: This is an open-access article distributed under the terms of the Creative Commons Attribution License, which permits unrestricted use, distribution, and reproduction in any medium, provided the original work is properly cited. 